\title{
Evaluation of Therapeutic Efficacy and Health Related Quality of Life of Anthracyclines Regimen and Taxanes with Anthracyclines Regimen in Node Positive Breast Cancer
}

\author{
Ponnusankar Sivasankaran*, Anjana Mohan \\ Department of Pharmacy Practice, JSS College of Pharmacy, Udhagamandalam, Nilgiris, Tamilnadu, INDIA.
}

\begin{abstract}
Background: Chemotherapy with anthracyclines/taxanes is considered as an effective treatment option for breast cancer. Adjuvant chemotherapeutic options with anthracyclines or taxanes have improved disease free survival and overall survival rates in early breast cancer. The study is aimed to compare the therapeutic efficacy of anthracyclines containing regimen and sequential administration of taxanes with anthracyclines regimen for NODE positive breast cancer patients and to assess the Health-Related Quality of Life (HROOL) of treated patients. Methods: This prospective open label study involved 14 patients who were treated with 6 cycles of 5-Fluorouracil $\left(500 \mathrm{mg} / \mathrm{m}^{2}\right)$, Doxorubicin $\left(50 \mathrm{mg} / \mathrm{m}^{2}\right)$, Cyclophosphamide $\left(500 \mathrm{mg} / \mathrm{m}^{2}\right)$ [FAC] and 10 patients with 6 cycles of FAC plus 4 cycles of Paclitaxel $\left(225 \mathrm{mg} / \mathrm{m}^{2}\right)$ [PAC]. Paired sample T test was used to assess the disease-free survival and reoccurrence rate. Time to progression was assessed by Kaplan Meir analysis and independent sample T test was used for assessing all the HRQOL parameters. Results: The disease-free survival was evaluated between the baseline and after 2 months of the chemotherapy which showed significant difference $(p<0.05)$ in the patients treated with FAC
\end{abstract}

regimen. Further, significant difference $(p<0.05)$ was also seen in the comparison of the first and end reports of chest $x$-ray during stage $3 \mathrm{~b}$. There was a significant improvement $(p<0.05)$ in the quality of life in the patients treated with FAC with adjuvant Paclitaxel during the $3^{\text {rd }}$ cycle. Conclusion: The study outcomes recommend that sequential administration of Paclitaxel with FAC can give more treatment benefit in stage 3 breast cancer.

Key words: Anthracyclines, Adjuvant therapy, Breast cancer, Disease free survival, HRQOL, taxanes.

\section{Correspondence}

Dr. Ponnusankar Sivasankaran, Professor and Head, Department of Pharmacy Practice, JSS College of Pharmacy, Udhagamandalam - 643 001, Nilgiris, Tamilnadu, INDIA.

Phone: +91-9489613428

Email: ponnusankarsivas@gmail.com

DOI: 10.5530/jyp.2019.11.37

\section{INTRODUCTION}

Breast cancer is the most common cancer among women in many developed and developing countries. Early diagnosis of the same may have diverse outcomes and responses to treatment. Chemotherapy with anthracyclines or taxanes is considered as an effective treatment option for early breast cancer, Human epidermal growth factor receptor (HER2) positive and Estrogen receptor (ER) positive patients with T3 and T4 staging. ${ }^{1}$ Last two decades, research studies have shown that addition of anthracyclines regimens is having favorable response in operable breast cancer. $^{2}$

In pre-menopausal and post-menopausal patients with advanced early breast cancer, 5-Fluorouracil $\left(500 \mathrm{mg} / \mathrm{m}^{2}\right)$, Doxorubicin $\left(50 \mathrm{mg} / \mathrm{m}^{2}\right)$, Cyclophosphamide $\left(500 \mathrm{mg} / \mathrm{m}^{2}\right)$ [FAC] is considered as one of the active regimens. Adjuvant chemotherapeutic option with anthracyclines or taxanes have improved disease free survival and overall survival rates in early breast cancer ${ }^{3}$ and also reduces the recurrence rate in women with operable breast cancer. ${ }^{4}$ Along with adjuvant Paclitaxel, addition of FAC after mastectomy has shown to improve the survival rate. ${ }^{5}$

Paclitaxel is used in the treatment of advanced breast cancer. Several studies have shown that Paclitaxel when used in the first line in metastatic breast cancer, the overall response rate have been $30-60 \%{ }^{6}$ while in second line setting the rate of overall response have been found to be $20-40 \% .^{7}$ In a study which included 4 cycles of FAC followed by 2 cycles of high dose Paclitaxel the complete response was $40 \% .{ }^{8}$ Improved benefit with better disease-free survival was noted during the adjuvant administration of taxane with anthracyclines. ${ }^{9}$
Assessment of health-related quality of life has become an important in the breast cancer for finding the patient outcome. ${ }^{10}$ The most important and common tool for assessing the health-related quality of life for cancer is European Organization for the Research and Treatment of Cancer Quality of Life Questionnaire version 3 (EORTC QLQ-C30). Some studies have shown that assessing the Quality of life (QoL) have also influenced the treatment schedule, decisions and the impact of the course of treatment. In the phase 3 trials, Health related quality of life (HRQoL) parameters are considered to be used for the assessing the endpoints. ${ }^{11}$ Patients treated with radiation have better functional scores and less symptom score indicating a better quality of life at the end of the treatment. The changes in the physical wellbeing, nausea and vomiting predict the recurrence of breast cancer. ${ }^{12}$

This study was aimed to compare the therapeutic efficacy of anthracyclines regimen and sequential administration of taxanes with anthracyclines regimen in node positive breast cancer and assessing the HRQoL of the patients.

\section{MATERIALS AND METHODS}

\section{Study design study population and data collection}

This study was an open label prospective quasi randomized study. The protocol was reviewed and approved by Institutional Review Board, JSS College of Pharmacy, Udhagamandalam (JSSCP/OT/DPP/IRB/00/2010-11 Dated: 30/08/2010). The patients were enrolled during the study period between August 2010 to April 2011. The node positive breast cancer 
patients with stage 2 and 3, palpable tumor mass, pre- or post-menopausal women, absence of distant metastasis; adequate cardiac, renal and hepatic functions, Karnofsky Performance Score $>70 \%$ were recruited. The subjects with cardiac disease, elevated levels of liver enzymes (bilirubin $>3 \mathrm{mg} / \mathrm{L}$, alkaline phosphatase ( $>1.5$ times the normal limit), aspartate aminotransferase ( $>1.5$ times the normal limit), renal function (inadequate serum creatinine level of $>1.5$ times the normal upper limit), inadequate bone marrow function, serious underlying medical illness, brain metastasis, pregnant patients were excluded from the study.

The potential study participants were screened for the eligibility criteria and 35 patients met the eligible criteria and agreed to be part of study and provided written informed consent in the language understood by them (in Tamil). The recruitment details, follow-up and the scheme of treatment received is presented in Figure 1.

\section{Treatment plan}

All the patients who were registered for the study were allocated to either of the group based on their preference of the treatment chosen. Before the initiation of the chemotherapy, 30-60 mins prior all the patients were administered with corticosteroids (Dexamethasone 20mg iv) and $\mathrm{H}_{2}$ antagonists (Ranitidine $50 \mathrm{mg}$ iv). After which the patients were given either of treatment of two cycles of Inj. 5-Fluorouracil $\left(500 \mathrm{mg} / \mathrm{m}^{2}\right)$, Inj. Doxorubicin $50 \mathrm{mg} / \mathrm{m}^{2}$, Inj. Cyclophosphamide $500 \mathrm{mg} / \mathrm{m}^{2}$ over $3-6 \mathrm{hrs}$ with 21 days $[\mathrm{FAC}]$ and other group received additionally Paclitaxel at a dose of $175 \mathrm{mg} / \mathrm{m}^{2}$ over $3 \mathrm{hrs}$. A data collection form was used to collect the demographic details, social-economic status and diet pattern. Complete physical examination, patient's history, laboratory details, chest x-ray, radio-isotope bone scan, Ultrasound scan (USG) abdomen scan was performed including EORTC-QLQ-C30 scored at base line visit and subsequently follow-up visit at second and third months.

\section{Outcome measurement}

The primary outcome measure included to estimate change in the score of quality of life using the European Organization for the Research and

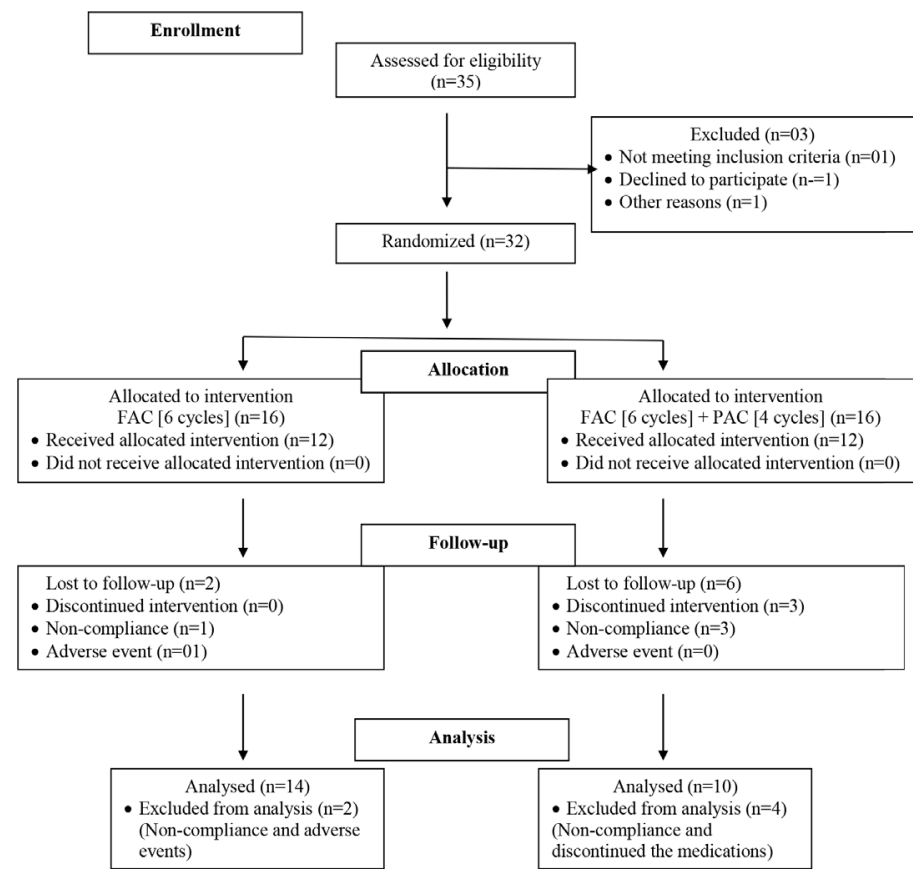

Figure 1: Scheme of the study and treatment.

${ }^{*} \mathrm{FAC}=5$-Fluorouracil; Doxorubicin; Cyclophosphamide; PAC - Paclitaxel.
Treatment of Cancer Quality of Life version 3.0 (EORTC QLQ- C30) questionnaires. The secondary outcome variable included to estimate the Overall survival (OS), defined as the time to death from time of randomization, Progression free survival (PFS) defined as from the time of randomization till the next radiographic of objective progression or else death from any other cause, Disease control rate (DCR) defined as the greatest tumor response of Partial response (PR), Complete response (CR) or Stable disease (SD) from baseline visit to study conclusion. The physician also checked to observe any side effects occurred during or after the treatment. If the side effects were experienced by the study participant, the same was documented with assessment of severity of the reaction and the causality assessment was performed.

\section{Statistical analysis}

The statistical analysis was carried out using SPSS version 19.0. Paired sample t-test, Kaplan Meir analysis, independent sample T test was used for the analysis of various parameters.

\section{RESULTS}

\section{Demography of the study}

Among the 24 patients who completed the study, the mean age of the patients was $56.62 \pm 6.67$ years and average body weight at baseline was $67.08 \pm 4.85 \mathrm{~kg}$. In the study demography, about $62.5 \%$ of the patients were in post-menopausal period, $41.6 \%$ of the patients were with the tumor size of more than $5 \mathrm{~cm}$ and $54.1 \%$ of the patients were having node involvement 2 . The clinical characteristics of the study subjects at baseline are represented in Table 1.

\section{Disease free survival}

The disease-free survival was evaluated between the baseline and after 2 months of the chemotherapy. The results concluded that there is a significant difference $(p<0.05)$ in the baseline $\left(\mathrm{V}_{0}\right)$ and at the end of two months (Vend) in the patients treated with FAC regimen. In the patients treated with adjuvant Paclitaxel with FAC did not show significant difference $(p>0.05)$ (Table 2).

\section{Recurrent rate}

In the present study, comparison of treatment with end reports and staging with end reports were performed with paired sample $\mathrm{T}$ test. When FAC and PAC with FAC was compared with the ultrasound, chest X-ray, radioisotope bone scan ( $1^{\text {st }}$ and end report) no significant difference $(p>0.05)$ were seen. Further, significant difference $(p<0.05)$ was seen in the comparison of the first and end reports of chest $\mathrm{x}$ - ray during stage $3 \mathrm{~b}$. It shows that disease progression i.e. lung metastasis was seen more in the stage $3 b$. In stage $2 a, 3 a, 3 b$ no significant difference $(p>0.05)$ was shown between $\mathrm{V}_{0}$ and $\mathrm{V}_{\text {end }}$ reports of ultrasound, $\mathrm{X}$ ray, radioisotope bone scan.

\section{Time to progression}

Kaplan Meier Analysis was done to find the time to treatment failure. The results show there is no significant difference $(p<0.01)$ between FAC and PAC with FAC treatment.

\section{Overall survival rate}

24 patients were enrolled in the study, of which 4 patients in FAC regimen having stage $2 \mathrm{a}, 4$ with stage $2 \mathrm{~b}, 2$ with stage $2 \mathrm{a}, 1$ with stage $3 \mathrm{a}$ and 5 with stage $3 \mathrm{~b}$. In PAC with FAC regimen 1 patient with stage $2 \mathrm{~b}$, 3 with stage $3 \mathrm{a}, 6$ with stage $3 \mathrm{~b}$. At the end of the study all patients were alive in both group i.e. 14 patients in FAC regimen and 10 patients in PAC with FAC regimen (Table 3). 
Table 1: Clinical characteristics of the recruited patients (at baseline).

\begin{tabular}{|c|c|}
\hline \multicolumn{2}{|c|}{ Patient Characteristics } \\
\hline Menopausal status & \\
\hline Premenopausal & $9(37.5 \%)$ \\
\hline Post-menopausal & $15(62.5 \%)$ \\
\hline \multicolumn{2}{|l|}{ Affected Breast } \\
\hline Left & $10(41.6 \%)$ \\
\hline Right & $14(58.3 \%)$ \\
\hline \multicolumn{2}{|l|}{ Tumor stage } \\
\hline 1 & $4(16.6 \%)$ \\
\hline 2 & $7(29.1 \%)$ \\
\hline 3 & $3(12.5 \%)$ \\
\hline 4 & $10(41.6 \%)$ \\
\hline \multicolumn{2}{|l|}{ Node involvement } \\
\hline 1 & $11(45.8 \%)$ \\
\hline 2 & $13(54.1 \%)$ \\
\hline \multicolumn{2}{|l|}{ Staging } \\
\hline 2 & $8(33.3 \%)$ \\
\hline 3 & $16(66.6 \%)$ \\
\hline 4 & $0(0 \%)$ \\
\hline \multicolumn{2}{|l|}{ Operation } \\
\hline Mastectomy & $24(100 \%)$ \\
\hline Lumpectomy & $0(0 \%)$ \\
\hline \multicolumn{2}{|l|}{ ECOG performance } \\
\hline 0 & $4(16.6 \%)$ \\
\hline 1 & $10(41.6 \%)$ \\
\hline 2 & $5(20.8 \%)$ \\
\hline 3 & $5(20.8 \%)$ \\
\hline \multicolumn{2}{|c|}{ Number of metastatic sites } \\
\hline 0 & $18(75 \%)$ \\
\hline 1 & $3(12.5 \%)$ \\
\hline 2 & $3(12.5 \%)$ \\
\hline \multicolumn{2}{|l|}{ Metastatic site } \\
\hline Lung & $5(20.8 \%)$ \\
\hline Bone & $2(8.3 \%)$ \\
\hline Liver & $2(8.3 \%)$ \\
\hline Brain & 0 \\
\hline \multicolumn{2}{|l|}{ Adjuvant therapy } \\
\hline Without Paclitaxel & $14(58.3 \%)$ \\
\hline With Paclitaxel & $10(41.6 \%)$ \\
\hline
\end{tabular}

Table 2: Comparison of disease-free survival in FAC and FAC+PAC.

\begin{tabular}{cccc}
\hline Treatment & Metastasis & Mean \pm SD & P value \\
\hline $\begin{array}{c}\text { FAC } \\
(n=14)\end{array}$ & Metastasis $\mathrm{V}_{0}$ & $0.00 \pm 0.000$ & $0.040^{*}$ \\
& Metastasis $\mathrm{V}_{\text {end }}$ & $0.29 \pm 0.469$ & \\
$\begin{array}{c}\text { FAC }+\mathrm{PAC} \\
(n=10)\end{array}$ & Metastasis $\mathrm{V}_{0}$ & $0.00 \pm 0.000$ & 0.168 \\
& Metastasis $\mathrm{V}_{\text {end }}$ & $0.20 \pm 0.422$ & \\
\hline
\end{tabular}

FAC $=5$-fluorouracil, Doxorubicin, Cyclophosphamide, $\mathrm{PAC}=$ Paclitaxel. ${ }^{*} P$ value $<0.05$ significant by paired sample $\mathrm{T}$ test.

\section{Health related quality of life}

The quality of life showed a significant difference $(p<0.05)$ after the third chemotherapy $\left(\mathrm{V}_{3}\right)$. The quality of life is found to be better with adjuvant Paclitaxel than FAC given alone during the course of the $3^{\text {rd }}$ chemotherapy and even after 2 months of chemotherapy. The FAC regimen had better physical, role function than adjuvant Paclitaxel. After two months of the chemotherapy the physical function improved in patients treated with adjuvant Paclitaxel, but it was not significant. The decline in the emotional function was found due to the increased adverse effects of the anthracyclines containing regimen. Social and cognitive function was not having significant difference between the two treatment groups. Fatigue, appetite loss, nausea and vomiting were significantly noted in the $3^{\text {rd }}$ chemotherapy with FAC group. Pain was significant in Paclitaxel group. Dyspnea, constipation, diarrhea, insomnia was noted in the patients, but it was not significant. A significant difference $(p<0.05)$ was shown in the financial difficulty during the course of chemotherapy and even after 2 months of the chemotherapy in both treatment groups (Table 4).

\section{DISCUSSION}

The results of the present study, showed the efficacy of 5-Fluorouracil, Doxorubicin, Cyclophosphamide (FAC) and adjuvant Paclitaxel with FAC in early and late stage breast cancer and provided an opportunity to assess the health-related quality of life using the questionnaire European Organization for the Research and treatment of Cancer Quality of Life version 3.0 (EORTC QLQ-C30). The study outcomes recommended that, in early stage breast cancer FAC is effective, while in advanced stage of breast cancer adjuvant therapy with Paclitaxel with FAC is having better outcome and lower rate of recurrence.

Adjuvant Paclitaxel had shown to prolong the disease-free survival. In FAC regimen, a significant difference $(p<0.05)$ in the disease-free survival was indicated showing that DFS had declined in FAC treated patients particularly in the locally advanced breast cancer. In patients treated with adjuvant Paclitaxel no significant difference $(p>0.05)$ was indicated. In FAC regimen 14 patients were enrolled of which 4 developed metastasis and 2 showed symptoms of recurrence. There were 6 DFS events in the FAC regimen. There were 2 DFS events in PAC with FAC regimen. The present study was in concordance with Mamounas EP et al. ${ }^{13}$ who conducted a study comparing Paclitaxel after Doxorubicin and Cyclophosphamide showing that sequential administration of Paclitaxel to anthracyclines reduces the risk of a DFS event.

Recurrence rate was significantly $(p<0.05)$ seen in the patients with $3 \mathrm{~b}$ stage of breast cancer. Among the 5 patients in stage $3 \mathrm{~b}$ treated with FAC regimen, 4 patients were having recurrence at the end of the study. In PAC with FAC group 6 patients were enrolled in stage 3b. 2 patients indicated recurrence at the end of the study. It shows that FAC was not having much efficacy in the locally advanced breast cancer when compared with adjuvant Paclitaxel, but it was not having significant difference $(p>0.05)$. No recurrence was seen in stage $2 \mathrm{a}$ and stage $2 \mathrm{~b}$ patients treated with FAC. It was an active regimen in early stage breast cancer. Mamounas et al. reported that Paclitaxel was beneficial for small tumors and for tumors of size more than $4 \mathrm{~cm}$ but not for intermediate size tumors. ${ }^{13}$ Dieras et al. conducted a study comparing the disease-free survival between Doxorubicin and Paclitaxel with Doxorubicin and Cyclophosphamide. ${ }^{14}$ DFS was found to be $87 \%$ in Doxorubicin and Paclitaxel and 79\% in Doxorubicin and Cyclophosphamide.

No significant difference was shown in the time to progression. The survival table indicates the time until the drug is having effect. Mean and median table for the survival time offers a quick comparison of time to effect of the medication. Since the significant values of the tests are all 
Table 3: Assessment of overall survival of the study participants.

\begin{tabular}{|c|c|c|c|c|c|c|c|}
\hline \multirow[t]{2}{*}{$\begin{array}{l}\text { Eastern Cooperative Oncology } \\
\text { Group performance scale }\end{array}$} & \multirow[t]{2}{*}{$\begin{array}{l}\text { Treatment- } \\
\text { Number of patients }\end{array}$} & \multirow[t]{2}{*}{$\begin{array}{l}\text { Time in } \\
\text { months }\end{array}$} & \multirow[t]{2}{*}{ Status } & \multicolumn{2}{|c|}{$\begin{array}{l}\text { Cumulative } \\
\text { proportion } \\
\text { surviving at } \\
\text { the time }\end{array}$} & \multirow[t]{2}{*}{$\begin{array}{l}\text { Number of } \\
\text { cumulative } \\
\text { events }\end{array}$} & \multirow[t]{2}{*}{$\begin{array}{c}\text { Number of } \\
\text { remaining } \\
\text { cases }\end{array}$} \\
\hline & & & & Estimate & Std Error & & \\
\hline \multirow[t]{3}{*}{ Restricted to do strenuous activity } & FAC & & & & & & \\
\hline & 1 & 2.1 & Metastasis & 0.667 & 0.272 & 1 & 2 \\
\hline & 2 & 6.0 & Non-metastasis & 0.333 & 0.272 & 2 & 1 \\
\hline \multirow[t]{2}{*}{ Unable to carry out any activity } & $\mathrm{FAC}+\mathrm{PAC}$ & & & & & & \\
\hline & 1 & 6.2 & Metastasis & 0.000 & 0.000 & 1 & 0 \\
\hline \multirow[t]{4}{*}{ Confined to bed } & FAC & & & & & & \\
\hline & 1 & 2 & Metastasis & - & - & 1 & 2 \\
\hline & 1 & 2 & Metastasis & 0.333 & 0.272 & 2 & 1 \\
\hline & 1 & 2 & Metastasis & 0.000 & 0.000 & 3 & 0 \\
\hline
\end{tabular}

Table 4: Assessment and comparison of quality of life of the study participants.

\begin{tabular}{|c|c|c|c|c|}
\hline \multirow{4}{*}{ Domain } & \multirow{4}{*}{ Visit } & \multicolumn{3}{|c|}{ Treatment } \\
\hline & & \multirow{3}{*}{$\begin{array}{c}\text { FAC } \\
(n=14) \\
\text { Mean } \pm \text { SD }\end{array}$} & \multirow[t]{2}{*}{ FAC + PAC $(n=10)$} & \multirow[b]{3}{*}{$P$-value } \\
\hline & & & & \\
\hline & & & Mean \pm SD & \\
\hline \multirow{3}{*}{$\begin{array}{l}\text { Quality of Life } \\
\text { (QoL) }\end{array}$} & $\mathrm{V}_{0}$ & $60.09 \pm 9.57$ & $10.97 \pm 10.97$ & 0.060 \\
\hline & $\mathrm{V}_{3}$ & $7.62 \pm 7.62$ & $11.81 \pm 11.81$ & $0.000^{*}$ \\
\hline & $\mathrm{V}_{\text {end }}$ & $18.11 \pm 18.11$ & $23.5 \pm 23.5$ & 0.080 \\
\hline \multirow[t]{3}{*}{ Physical function } & $\mathrm{V}_{0}$ & $93.82 \pm 7.45$ & $85.96 \pm 7.97$ & $0.024^{*}$ \\
\hline & $\mathrm{V}_{3}$ & $75.60 \pm 8.83$ & $59.31 \pm 4.91$ & $0.000^{*}$ \\
\hline & $\mathrm{V}_{\text {end }}$ & $84.73 \pm 19.31$ & $89.32 \pm 14.81$ & 0.536 \\
\hline \multirow[t]{3}{*}{ Role function } & $\mathrm{V}_{0}$ & $93.57 \pm 10.86$ & $91.6 \pm 8.80$ & 0.653 \\
\hline & $\mathrm{V}_{3}$ & $71.37 \pm 10.20$ & $46.62 \pm 10.58$ & $0.000^{*}$ \\
\hline & $\mathrm{V}_{\text {end }}$ & $83.3 \pm 17.31$ & $91.66 \pm 21.16$ & 0.299 \\
\hline \multirow{3}{*}{$\begin{array}{l}\text { Emotional } \\
\text { function }\end{array}$} & $\mathrm{V}_{0}$ & $35.22 \pm 9.10$ & $43.30 \pm 16.57$ & 0.150 \\
\hline & $\mathrm{V}_{3}$ & $46.39 \pm 13.74$ & $63.31 \pm 16.77$ & $0.013^{*}$ \\
\hline & $\mathrm{V}_{\text {end }}$ & $62.47 \pm 22.58$ & $72.4 \pm 24.55$ & 0.315 \\
\hline \multirow[t]{3}{*}{ Cognitive function } & $\mathrm{V}_{0}$ & $100 \pm 0.00$ & $100 \pm 0.00$ & -- \\
\hline & $\mathrm{V}_{3}$ & $95.22 \pm 0.156$ & $100 \pm 0.00$ & 0.014 \\
\hline & $\mathrm{V}_{\text {end }}$ & $91.65 \pm 14.2$ & $96.6 \pm 7.04$ & 0.270 \\
\hline \multirow[t]{3}{*}{ Social function } & $\mathrm{V}_{0}$ & $87.15 \pm 13.89$ & $72.45 \pm 11.16$ & $0.013^{*}$ \\
\hline & $\mathrm{V}_{3}$ & $66.61 \pm 14.62$ & $63.29 \pm 10.51$ & 0.514 \\
\hline & $\mathrm{V}_{\text {end }}$ & $78.53 \pm 20.09$ & $88.32 \pm 19.34$ & 0.245 \\
\hline \multirow[t]{3}{*}{ Fatigue } & $\mathrm{V}_{0}$ & $10.24 \pm 19.47$ & $5.55 \pm 10.78$ & 0.502 \\
\hline & $\mathrm{V}_{3}$ & $72.03 \pm 13.01$ & $28.64 \pm 22.65$ & $0.000^{*}$ \\
\hline & $\mathrm{V}_{\text {end }}$ & $14.11 \pm 19.39$ & $13.10 \pm 29.35$ & 0.919 \\
\hline \multirow{3}{*}{$\begin{array}{l}\text { Nausea and } \\
\text { vomiting }\end{array}$} & $\mathrm{V}_{0}$ & $0.692 \pm 2.49$ & $1.11 \pm 3.5$ & 0.490 \\
\hline & $\mathrm{V}_{3}$ & $7.13 \pm 10.19$ & $22.7 \pm 24.06$ & $0.000^{*}$ \\
\hline & $V_{\text {end }}$ & $5.94 \pm 12.4$ & $4.44 \pm 14.04$ & 0.784 \\
\hline \multirow[t]{3}{*}{ Pain } & $\mathrm{V}_{0}$ & $59.45 \pm 10.67$ & $49.98 \pm 26.05$ & 0.246 \\
\hline & $\mathrm{V}_{3}$ & $44.85 \pm 16.52$ & $69.97 \pm 18.91$ & $0.002^{*}$ \\
\hline & $V_{\text {end }}$ & $23.79 \pm 31.13$ & $13.33 \pm 29.17$ & 0.414 \\
\hline \multirow[t]{3}{*}{ Appetite loss } & $\mathrm{V}_{0}$ & $0.000 \pm 0.00$ & $0.000 \pm 0.00$ & -- \\
\hline & $\mathrm{V}_{3}$ & $76.14 \pm 15.65$ & $16.65 \pm 17.55$ & $0.000^{*}$ \\
\hline & $\mathrm{V}_{\text {end }}$ & $14.27 \pm 17.10$ & $6.66 \pm 14.04$ & 0.261 \\
\hline \multirow[t]{3}{*}{ Dyspnoea } & $\mathrm{V}_{0}$ & $0.00 \pm 0.00$ & $0.00 \pm 0.00$ & -- \\
\hline & $\mathrm{V}_{3}$ & $7.13 \pm 14.17$ & $3.33 \pm 10.53$ & 0.481 \\
\hline & $\mathrm{V}_{\text {end }}$ & $11.89 \pm 24.80$ & $9.9 \pm 22.47$ & 0.847 \\
\hline
\end{tabular}

greater than 0.10 , there is no difference between the survival curves. No significant difference was noted in the overall survival rate in the FAC and PAC with FAC group.

In this study, disease specific quality of life questionnaire EORTC QLQC30 was used which have a quality of life question, functioning scale, symptom scale and single item scales. There was a significant improvement $(p<0.05)$ in the quality of life in the patients treated with adjuvant Paclitaxel during the $3^{\text {rd }}$ cycle. Even after the chemotherapy the quality of life was improved in the Paclitaxel group. Takahashi et al. reported that anxiety during the diagnosis, chemotherapy and post treatment also negatively influences the quality of life. ${ }^{15}$ The physical function and social function showed significant difference $(p<0.05)$ in the baseline scores. The physical function and role function declined significantly $(p<0.05)$ during the $3^{\text {rd }}$ chemotherapy in the treatment group with adjuvant Paclitaxel as compared with FAC given alone. These findings are in correlation with the study done by Bottomley A et al. who reported a reduction in the physical and role function in the patients treated with Doxorubicin and Paclitaxel after the $2^{\text {nd }}$ cycle of chemotherapy and improves after the $4^{\text {th }}$ cycle. ${ }^{16}$ After the treatment the role function and physical function improved. Emotional function declined in the patients treated with FAC during the $3^{\text {rd }}$ course of chemotherapy. A decline in the cognitive function was noted in the advanced stage of breast cancer. Even after the chemotherapy cognitive function declined in some patients indicating the disease progression i.e. metastatic breast cancer.

Fatigue, nausea and vomiting was significantly more $(p<0.05)$ in the patients treated with FAC regimen during the course of the $3^{\text {rd }}$ chemotherapy which reduced after the course of the chemotherapy. Stone P et al. ${ }^{17}$ reported that fatigue is one of the untreated symptoms of cancer and it affects the quality of life to a greater extent. Safee et al. ${ }^{18}$ reported that the adverse effects and various symptoms during the chemotherapy influenced the quality of life. Kramer JA et al. ${ }^{19}$ conducted a randomized trial to evaluate the quality of life in patients treated with Paclitaxel and Doxorubicin which shows a significant difference in the nausea, vomiting, fatigue with the doxorubicin arm and lack of nausea and vomiting in the arm treated with Paclitaxel. Locally advanced breast cancer patients showed nausea and fatigue even after two months of the chemotherapy indicating the disease progression. It also indicates that FAC regimen was not much efficacious in the patients with advanced stage of breast cancer. Pain was significantly more $(p<0.05)$ in the treatment group with Paclitaxel which reduced after the chemotherapy. Sarenmalm EK et al. ${ }^{20}$ conducted a study which reported that fatigue, cognitive impairment, 
pain, feeling sad, anxiety are some indications of the recurrent breast cancer.

Diarrhea was more frequent for the patients treated with FAC, but it was not significant $(p>0.05)$ and improved after the chemotherapy. Constipation was more common with adjuvant Paclitaxel, but it was not significant ( $p>0.05)$. Appetite loss was significant $(p<0.05)$ during the course of the $3^{\text {rd }}$ chemotherapy. Appetite loss was more significant with FAC regimen as compared with that of adjuvant Paclitaxel. It improved after the course of the chemotherapy.

Dyspnea was not significantly $(p>0.05)$ present during the chemotherapy. After 2 months of the chemotherapy dyspnea was seen in some patients due to lung metastasis. FAC regimen showed increased rate of dyspnea indicating that more patients treated in the advanced stage had disease progression. Insomnia was noted in some patients who had metastasis, but it was not having significant value $(p>0.05)$.

Patients treated with FAC and adjuvant Paclitaxel faced significant financial difficulty during the $3^{\text {rd }}$ chemotherapy and even after the chemotherapy. An increase in the financial difficulty is seen in both groups with more adverse effect in the Paclitaxel group. Financial problem have limited some patients from taking the adjuvant Paclitaxel inspite of their advanced stage of the disease. With the questionnaire the study concluded that adjuvant Paclitaxel is an effective regimen in breast cancer.

\section{CONCLUSION}

The study outcomes recommend that in locally advanced breast cancer sequential administration of Paclitaxel with FAC showed a significance difference in the disease-free survival; time to progression; recurrence rate and health related quality of life.

\section{ACKNOWLEDGEMENT}

The authors wish to thank all the study participants for their cooperation and permission to carry out this work.

\section{CONFLICT OF INTEREST}

The authors declare no conflict of interest.

\section{ABBREVIATIONS}

ER: Estrogen Receptor; HER2: Human Epidermal Growth Factor Receptor; EORTC QLQ-C30: European Organization for the Research and Treatment of Cancer Quality of Life Questionnaire version 3; QoL: Quality of Life; HRQoL: Health related quality of life; USG: Ultra sound scan; DCR: Disease Control Rate; OS: overall Survival; PFS: Progression Free Survival; PR: Partial Response; CR: Complete Response; SD: Stable Disease; DFS: Disease Free Survival.

\section{REFERENCES}

1. Gianni L, Valagussa P. Anthracyclines and early breast cancer: the end of an era? J Clin Oncol. 2009;27(8):1155-57.

2. Livi L, Meattini I, Saieva C, Borghesi S, Scotti V, Petrucci A, et al. The impact of young age on breast cancer outcome. Eur J Surg Oncol. 2010;36(7):639-45.

3. Early Breast Cancer Trialists' Collaborative Group (EBCTCG). Effects of chemo- therapy and hormonal therapy for early breast cancer on recurrence and 15-year survival: An overview of the randomized trials. Lancet. 2005;365(9472):1687-717.

4. Bria E, Nistico C, Cuppone F, Carlini P, Ciccarese M, Milella M, et al. Benefit of taxanes as adjuvant chemotherapy for early breast cancer: pooled analysis of 15,500 patients. Cancer. 2006;106(11):2337-44.

5. Gnant M, Steger GG. Fighting over treatment in adjuvant breast cancer therapy Lancet. 2009;374(9707):2029-30.

6. Smith RE, Brown AM, Mamounas EP, Anderson SJ, Lembersky BC, Atkins JH, et al. Randomized trial of 3-hr versus 24-hr infusion of high-dose paclitaxel in patients with metastatic or locally advanced breast cancer: National Surgical Adjuvant Breast and Bowel Project Protocol B-26. J Clin Oncol. 1999;17(11):3403-11.

7. White J, Howells A, Jones A, Poole C, Lind M, Stuart N, et al. A multicenter phase II pilot study of Epirubicin and Taxol (Paclitaxel) in patients with advanced breast cancer. Clin Oncol. 2000;12(4):256-9.

8. Lück HJ, Roché H. Weekly Paclitaxel: an effective and well-tolerated treatment in patients with advanced breast cancer. Crit Rev Oncol Hematol. 2002;44(Supp I):S15-30.

9. Henderson IC, Berry DA, Demetri GD, Cirrincione CT, Goldstein LJ, Martino S, et al. Improved outcomes from adding sequential Paclitaxel but not from escalating Doxorubicin dose in an adjuvant chemotherapy regimen for patients with node-positive primary breast cancer. J Clin Oncol. 2003;21(6):976-83.

10. Greenfield S, Nelson EC. Recent developments and future issues in the use of health status assessment measures in clinical setting. Med Care. 1992;30(5 Suppl):MS23-41.

11. Adamowicz K, Jassem J, Katz A, Saad ED. Assessment of quality of life in advanced breast cancer: an overview of randomized phase III trials. Cancer Treat Rev. 2012;38(5):554-8

12. Sarenmalm EK, Odén A, Ohlén J, Gaston-Johansson F, Holmberg SB. Changes in health-related quality of life may predict recurrent breast cancer. Eur $\mathrm{J}$ Oncol Nurs. 2009;13(5):323-9.

13. Mamounas EP, Bryant J, Lembersky B, Fehrenbacher L, Sedlacek SM, Fisher B, et al. Paclitaxel after doxorubicin plus cyclophosphamide as adjuvant chemotherapy for node-positive breast cancer: results from NSABP B-28. J Clin Oncol. 2005;23(16):3686-96

14. Diéras V, Fumoleau P, Romieu G, Tubiana-Hulin M, Namer M, Mauriac L, et al. Randomized parallel study of doxorubicin plus paclitaxel and doxorubicin plus cyclophosphamide as neoadjuvant treatment of patients with breast cancer. $J$ Clin Oncol. 2004;22(24):4958-65.

15. Takahashi T, Hondo M, Nishimura K, Kitani A, Yamano T, Yanagita H, et al. Evaluation of quality of life and psychological response in cancer patients treated with radiotherapy. Radiat Med. 2008;26(7):396-401.

16. Bottomley A, Biganzoli L, Cufer T, Coleman RE, Coens C, Efficace F, et al. Randomized, controlled trial investigating short-term health-related quality of life with doxorubicin and paclitaxel versus doxorubicin and cyclophosphamide as first-line chemotherapy in patients with metastatic breast cancer: European Organization for Research and Treatment of Cancer Breast Cancer Group, Investigational Drug Branch for Breast Cancer and the New Drug Development Group Study. J Clin Oncol. 2004;22(13):2576-86.

17. Stone P. The measurement causes and effective management of cancer-related fatigue. Int J Palliat Nurs. 2002;8(3):120-8.

18. Safaee A, Moghimi-Dehkordi B, Zeighami B, Tabatabaee H, Pourhoseingholi M. Predictors of quality of life in breast cancer patients under chemotherapy. Indian J Cancer. 2008;45(3):107-11.

19. Kramer JA, Curran D, Piccart M, DeHaes JC, Bruning PF, Klijn JG, et al. Randomized trial of paclitaxel versus doxorubicin as first-line chemotherapy for advanced breast cancer: quality of life evaluation using the EORTC QLQ-C30 and the Rotterdam symptom checklist. Eur J Cancer. 2000;36(12):1488-97.

20. Sarenmalm EK, Ohlén J, Jonsson T, Gaston-Johansson F. Coping with recurrent breast cancer: predictors of distressing symptoms and health-related quality of life. J Pain Symptom Manage. 2007;34(1):24-39.

Article History: Submission Date : 02-09-2018; Revised Date : 15-11-2018; Acceptance Date : 25-01-2019

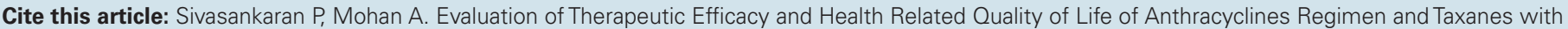
Anthracyclines Regimen in Node Positive Breast Cancer. J Young Pharm. 2019;11(2):177-81. 